\title{
A Study to Draw a Normative Database of Laryngopharynx pH Profile in Chinese
}

\author{
Guijian Feng, ${ }^{1 *}$ Junyao Wang, ${ }^{1}$ Lihong Zhang $^{2}$ and Yulan Liu ${ }^{1}$ \\ Departments of ${ }^{1}$ Gastroenterology and ${ }^{2}$ Otorhinolaryngology, Peking University People's Hospital, Beijing, China
}

\section{Background/Aims}

To draw a normative database of laryngopharynx pH profile in Chinese subjects.

\section{Methods}

Normal volunteers were recruited from "www.Ganji.com" and People's hospital between May 2008 and December 2009. The Restech pH Probes were calibrated in $\mathrm{pH} 7$ and $\mathrm{pH} 4$ buffer solutions according to the manufacturer's instructions. Each volunteer was asked to wear the device for a 24-hour period and was encouraged to participate in normal daily activities.

\section{Results}

The healthy volunteers consisted of 20 males and 9 females with a median age of 23 years (interquartile range, 21 to 32 years). The 95th percentiles for \% total times at $\mathrm{pH}<4, \mathrm{pH}<4.5, \mathrm{pH}<5.0$ and $\mathrm{pH}<5.5$ for the oropharynx $\mathrm{pH}$ catheter were $0.06 \%, 1.01 \%, 7.23 \%$ and $27.34 \%$, respectively. The 95 th percentile for number of reflux events within the 24-hour period at $\mathrm{pH}<4, \mathrm{pH}<4.5, \mathrm{pH}<5.0$ and $\mathrm{pH}<5.5$ were 2.0, 18.0, 107.5 and 284.5, respectively.

\section{Conclusions}

This is the first study to systematically assess the degree of reflux detected by the new $\mathrm{pH}$ probe in healthy asymptomatic Chinese volunteers and to report normative values in Chinese people. Using an oropharyngeal pH catheter to monitor laryngopharyngeal reflux indicated that in healthy Chinese, reflux should be considered normal if the percent time at $\mathrm{pH}$ less than 4.5 is no more than $1 \%$.

\section{(J Neurogastroenterol Motil 2014;20:347-351)}

\section{Key Words}

Esophageal pH monitoring; Gastroesophageal reflux; Laryngopharyngeal reflux

Received: December 31, 2013 Revised: March 5, 2014 Accepted: March 14, 2014

(c) This is an Open Access article distributed under the terms of the Creative Commons Attribution Non-Commercial License (http://creativecommons. org/licenses/by-nc/3.0) which permits unrestricted non-commercial use, distribution, and reproduction in any medium, provided the original work is properly cited.

*Correspondence: Guijian Feng, MD

Department of Gastroenterology, Peking University People's Hospital, No 11, Xizhimen, South Street, Beijing 100044, China Tel: +86-10-8832-5388, Fax: +86-10-6831-8386, E-mail: fggods@126.com

Financial support: Respiratory Technology Corporation provided the Dx-pH Measurement System dx-pH system and volunteers' traffic fee. Conflicts of interest: None.

Author contributions: Guijian Feng, planning and conducting the study, collecting and interpreting data, and drafting the manuscript; Junyao Wang, collecting and interpreting data, and drafting the manuscript; Lihong Zhang, collecting data; Yulan Liu, planning and conducting the study.

ORCID: Guijian Feng, http://orcid.org/0000-0002-6400-847X. 


\section{Introduction}

Gastroesophageal reflux disease (GERD) is a condition that develops due to reflux of stomach contents into the esophagus, oral cavity (including larynx) or lung. ${ }^{1}$ GERD is a common disease in Western countries and in Asia. ${ }^{2}$ Epidemiologic studies suggest that close to $50 \%$ of the population may have some type of GERD symptom during a calendar year. ${ }^{3}$ Wong et $\mathrm{al}^{4}$ reported that approximately $29.8 \%$ of the population in China suffers from GERD symptoms in an annual period. Ma et $\mathrm{al}^{5}$ found that the prevalence of GERD, defined $^{6}$ as heartburn and/or regurgitation of any frequency during the previous week, was $6.2 \%$ in Shanghai, a developed city in China. Laryngopharyngeal reflux (LPR) is the backflow of gastric contents (refluxate) to the laryngopharynx and upper aerodigestive tract and by a recent definition is a form of GERD. ${ }^{7}$ LPR is not always secondary to $\mathrm{GERD}^{8}$; however the term laryngopharyngeal reflux disease (LPRD) was adopted by the American Academy of Otolaryngology-Head and Neck Surgery in its 2002 Position Statement on LPR. ${ }^{9}$ We presented our classification of LPRD in a previous conference abstract. ${ }^{10}$ The diagnosis of LPRD is mainly based on reflux symptom index, ${ }^{11}$ reflux finding score (RSF) ${ }^{12}$ and laryngopharynx $\mathrm{pH}$ monitoring. The susceptibility of larygopharyngeal epithelium to reflux injury differs from that of esophagus ${ }^{13}$ and the normative data of reflux events may vary by ethnicity or diet.

Normative LPR data are available for many groups, ${ }^{14,15}$ but there is no accepted normal larygopharyngeal $\mathrm{pH}$ profile for healthy Chinese subjects. To determine the normal values of $\mathrm{pH}$ in healthy Chinese, we used the Dx-pH measurement system (Respiratory Technology Corp, San Diego, CA, USA). The $\mathrm{Dx}-\mathrm{pH}$ probe is a sensitive and minimally invasive device for detection of acid reflux in the posterior oropharynx. ${ }^{16}$ It uses a nasopharyngeal catheter to measure $\mathrm{pH}$ in either liquid or aerosolized droplets. Special circuitry monitors each individual reading to assure sufficient sensor hydration. This circuitry prevents the inclusion of dry-out related "pseudo-reflux" events. Our study provides the first normative LPR data for healthy Chinese subjects.

\section{Materials and Methods}

\section{Study Population}

The study protocol was approved by the institutional review board for human use at People's Hospital, Peking University and informed consent was obtained from each participant. Normal volunteers were recruited from "www.Ganji.com" and People's Hospital between May 2008 and December 2009. Each potential subject completed reflux symptom index ${ }^{11}$ and reflux disease questionnaire. Only volunteers with scores equal to zero participated in the study. Subjects with history of GERD or laryngopharyngeal diseases or who had recently used histamine receptor antagonists, proton pump inhibitors, or other antacids were also excluded. Each volunteer underwent laryngoscope examination, and only those who presented with no abnormalities and with $\mathrm{RSF}^{12}$ score of zero were studied. Additional exclusion criteria included ongoing use of alcohol or tobacco, inability to comply with the period of monitoring (22-24 hours), recent nasal surgery or nasal obstruction, or other significant medical conditions (psychiatric disorders, inability to comprehend the consent form and pregnancy).

\section{Study Design}

The Restech $\mathrm{pH}$ probes were calibrated in $\mathrm{pH} 7$ and $\mathrm{pH} 4$ buffer solutions according to the manufacturer's instructions. The probe is a $1.5 \mathrm{~mm}$ diameter oropharyngeal catheter with a wireless digital transmitter worn externally. The catheter employs a $3.2 \mathrm{~mm}$ teardrop-like tip that contains a colored light emitting diode (LED) to aid insertion and to allow visualization of the sensor for proper positioning. The standard catheter was placed in the oropharynx at the level of the uvula. Each volunteer was asked to wear the device for a 24-hour period and was encouraged to participate in normal daily activities. Each subject carried one transmitter/receiver that wirelessly sent data to a monitor worn by the subject. The monitor contains a digital memory card to record events such as meal times, position and chief complaint. Once the $\mathrm{pH}$ study was completed, the volunteer returned to have the catheter removed, and the data from the digital recorder were downloaded to a password-protected computer. Data were analyzed with DataView software (version 3; AEMC Instruments, Dover, NH, USA). The software generated a graphical tracing of the study events and also created a report of any reflux events. The data collected during meal times were excluded from analysis. It was considered as reflux event when the time of $\mathrm{pH}$ reaching to the lowest point was no more than 30 seconds.

\section{Statistical Methods}

Data are presented as means or medians depending on data distribution, and 25 th, 75 th and 95th percentiles are provided. The percent time spent below $\mathrm{pH}$ values of 4.0, 4.5, 5.0 and 5.5 


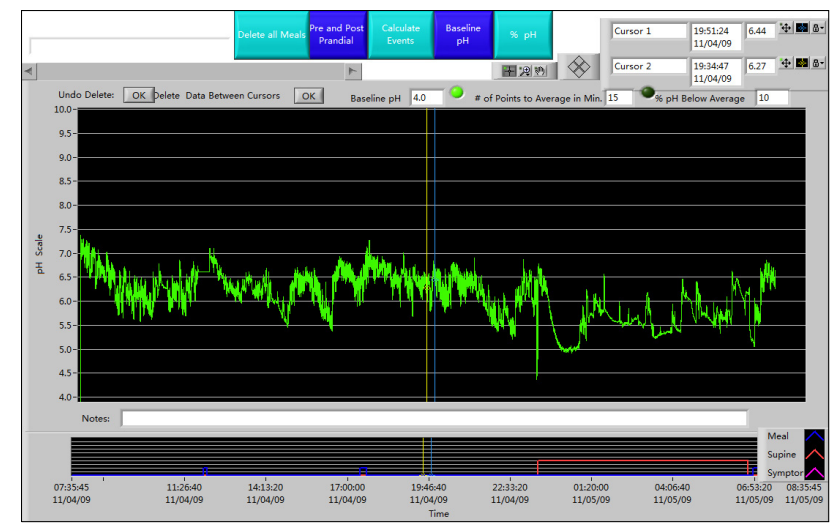

Figure 1. Oropharyngeal $\mathrm{pH}$ monitored over the course of 24 hours in a healthy volunteer.

was determined for each subject. The data were also evaluated based on whether the subject was in the upright position, a supine position or a combination of the 2 positions (total). The distributions of percent time were summarized at 25th, 50th (median), 75th and 95th quantiles for each $\mathrm{pH}$ level and body position. All data were visually evaluated for accuracy by one investigator and subjects were excluded if they were not monitored for at least 22 hours. This allowed analysis of both supine and upright positions.

\section{Results}

Of 90 volunteers initially recruited, 50 subjects were excluded due to self-report of one or more GERD or LPR symptoms or because of treatment with acid suppressive therapy. An additional 10 subjects were excluded because of one or more RSF signs by laryngoscope. Thirty volunteers began $\mathrm{pH}$ monitoring. One volunteer withdrew due to dizziness an hour after initial placement. Thus a total of 29 healthy volunteers constituted the study population and underwent $\mathrm{pH}$ monitoring with a Restech $\mathrm{pH}$ catheter in the oropharynx. The healthy volunteers consisted of 20 males and 9 females with a median age of 23 years (interquartile range, 21 to 32 years). No patient reported heartburn, cough, globus or throat discomfort during the study period. Figure 1 shows a typical tracing of oropharyngeal $\mathrm{pH}$ monitoring in a healthy volunteer. In Figure 2, the raw data from Figure 1 has been subjected to analysis.

A summary of the data obtained using the oropharyngeal $\mathrm{pH}$ catheter for all 29 subjects is shown in Table. The 95th percentiles for $\%$ total time at $\mathrm{pH}<4.0, \mathrm{pH}<4.5, \mathrm{pH}<5.0$ and $\mathrm{pH}<5.5$ were $0.06 \%, 1.01 \%, 7.23 \%$ and $27.34 \%$, respectively.

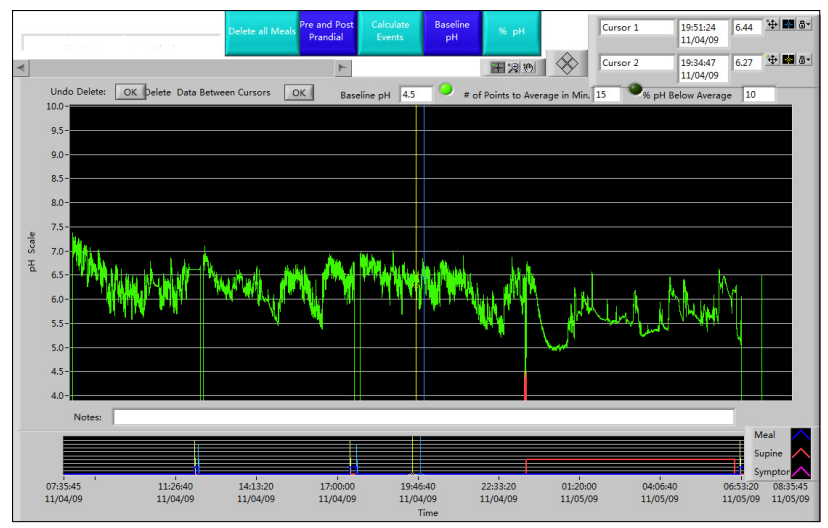

Figure 2. An analysis of the data shown in Figure 1. The data collected during meals were deleted, and $\mathrm{pH} 4.5$ was selected as baseline $\mathrm{pH}$. The time duration for analysis was 22 hours and 51 minutes. The percentile for $\%$ total time at $\mathrm{pH}<4.5$ was 0.02 , and 2 reflux events. The part of the curve marked by red vertical lines is reflux curve.

Table also shows the number of reflux events at each $\mathrm{pH}$ level for total, upright and supine positions. The 95 th percentiles for the number of reflux events for $\mathrm{pH}<4.0, \mathrm{pH}<4.5$, $\mathrm{pH}<5.0$ and $\mathrm{pH}<5.5$ were $2.5,18.0,107.5$ and 284.5, respectively.

\section{Discussion}

Chinese researchers began to study LPR many years ago. In 1995, Zheng et al. found that abnormal sensations in the pharynx were associated with the esophageal $\mathrm{pH} .{ }^{17}$ Cheng et al ${ }^{18}$ found that $17.9 \%$ of GERD patients suffered from cough and asthma. ${ }^{18}$ We previously reported an association of oropharyngeal $\mathrm{pH}$ with $\mathrm{LPR}^{19}$ and analyzed the relationship of GERD and LPR based on symptoms. ${ }^{20}$ Another researcher determined the clinical value of $24 \mathrm{~h}$ double-probe $\mathrm{pH}$-metry for the diagnosis and treatment of LPR. ${ }^{21}$ Despite of the presentation of these studies, normal values of oropharyngeal $\mathrm{pH}$ in the Chinese population have not been established. However normal oropharyngeal $\mathrm{pH}$ profiles have been obtained in other country. ${ }^{15}$ In this previous study, a distal esophageal catheter was used to ensure that the decrease in $\mathrm{pH}$ detected by the oropharyngeal $\mathrm{pH}$ catheter originated distally and was of a gastric source. However, LPR is not always secondary to gastroesophageal reflux and the association between heterotopic gastric mucosal patch and LPR has been reported. ${ }^{22,23}$ Here we used an oropharyngeal $\mathrm{pH}$ catheter to ensure that all LPR events were detected. The volunteers in our study were evaluated by laryngoscopy to exclude silent LPR patients.

Wang et $\mathrm{al}^{24}$ performed ambulatory 24-hour multichannel 
Table. Oropharyngeal pH Parameters Detected by Restech pH Probe $(\mathrm{N}=29)$

\begin{tabular}{|c|c|c|c|c|c|c|}
\hline Item & Posture & Mean & $25 \%$ percentile & Median & $75 \%$ percentile & $95 \%$ percentile \\
\hline \multirow[t]{3}{*}{$\%$ time $<\mathrm{pH} 4.0$} & Upright & 0.01 & 0.00 & 0.00 & 0.00 & 0.10 \\
\hline & Supine & 0.15 & 0.00 & 0.00 & 0.00 & 2.25 \\
\hline & Total & 0.04 & 0.00 & 0.00 & 0.00 & 0.64 \\
\hline \multirow[t]{3}{*}{$\%$ time $<\mathrm{pH} 4.5$} & Upright & 0.04 & 0.00 & 0.00 & 0.00 & 0.41 \\
\hline & Supine & 0.24 & 0.00 & 0.00 & 0.00 & 3.37 \\
\hline & Total & 0.09 & 0.00 & 0.00 & 0.03 & 1.01 \\
\hline \multirow[t]{3}{*}{$\%$ time $<\mathrm{pH} 5.0$} & Upright & 0.27 & 0.00 & 0.00 & 0.07 & 3.41 \\
\hline & Supine & 2.41 & 0.00 & 0.00 & 2.27 & 19.06 \\
\hline & Total & 0.98 & 0.00 & 0.05 & 0.69 & 7.23 \\
\hline \multirow[t]{3}{*}{$\%$ time $<$ pH 5.5} & Upright & 2.28 & 0.04 & 0.28 & 2.10 & 18.97 \\
\hline & Supine & 19.68 & 0.00 & 16.50 & 31.91 & 58.60 \\
\hline & Total & 8.23 & 0.20 & 8.66 & 13.10 & 27.34 \\
\hline \multirow[t]{3}{*}{ No. of events $\mathrm{pH}<4.0$} & Upright & 0.8 & 0.0 & 0.0 & 0.0 & 2.0 \\
\hline & Supine & 0.0 & 0.0 & 0.0 & 0.0 & 0.5 \\
\hline & Total & 0.2 & 0.0 & 0.0 & 0.0 & 2.5 \\
\hline \multirow[t]{3}{*}{ No. of events $\mathrm{pH}<4.5$} & Upright & 0.6 & 0.0 & 0.0 & 0.0 & 5.5 \\
\hline & Supine & 1.1 & 0.0 & 0.0 & 0.0 & 15.5 \\
\hline & Total & 1.7 & 0.0 & 0.0 & 1.0 & 18.0 \\
\hline \multirow[t]{3}{*}{ No. of events $\mathrm{pH}<5.0$} & Upright & 3.2 & 0.0 & 0.0 & 3.0 & 28.0 \\
\hline & Supine & 10.8 & 0.0 & 0.0 & 5.5 & 88.0 \\
\hline & Total & 13.7 & 0.0 & 1.0 & 8.0 & 107.5 \\
\hline \multirow[t]{3}{*}{ No. of events $\mathrm{pH}<5.5$} & Upright & 44.5 & 0.0 & 5.0 & 80.0 & 207.0 \\
\hline & Supine & 45.8 & 0.0 & 44.0 & 75.5 & 116.0 \\
\hline & Total & 85.8 & 7.5 & 56.0 & 129.5 & 284.5 \\
\hline
\end{tabular}

intraluminal impedance-pH (MII-pH) monitoring in a group of healthy Chinese volunteers to define the normative data of LPR. A limitation of the Wang study is that the MII-pH probe monitors both pharynx and esophagus, defining LPR as gastroesophageal reflux that reaches $1 \mathrm{~cm}$ above the upper esophageal sphincter. This design may miss LPR events. In another study, laryngopharyngeal reflux was studied in 20 volunteers, ${ }^{15} \mathrm{pH}$ monitoring time was from 14 to 24 hours (median 20.5 hours). The 95th percentile for percent total times at $\mathrm{pH}<4, \mathrm{pH}<5$ and $\mathrm{pH}<6$ were $0.02 \%, 2.33 \%$ and $21.41 \%$, respectively. The 95th percentile for number of reflux events at $\mathrm{pH}<4, \mathrm{pH}<5$ and $\mathrm{pH}<6$ were 1.3, 8.1 and 128.0, respectively. The values in our study were higher than these when the same $\mathrm{pH}$ value was used as baseline. In the previous study, the authors did not report data of $\mathrm{pH}$ values at 4.5 or 5.5 and in some subjects $\mathrm{pH}$ monitoring time was less than 22 hours.

The advantages of our study are mainly derived from the probe employed. When a traditional $\mathrm{pH}$ sensor is utilized in monitoring pharyngeal $\mathrm{pH}$, data are noisy due to mucus accumulation, food interruption and sensor drying; this noise cannot be completely corrected thereby making data analysis complicated. ${ }^{25}$ The Restech $\mathrm{pH}$ probe used here is specially designed for measurement of pharyngeal $\mathrm{pH}$. Data are collected only when the probe is dry, which significantly minimizes artifacts. Moreover, the Restech $\mathrm{pH}$ probe samples at a frequency of $2 \mathrm{~Hz}$ (i.e., once every 0.5 second), whereas a traditional probe has a 4 - to 5 -second interval. This high rate of sampling enables the device to draw a more accurate profile of pharyngeal environment. ${ }^{16}$

In our study, volunteers did not undergo esophageal manometry or esophagogram. All the volunteers who had reported any discomfort or symptom were not included. Therefore, it is unlikely that any of our subjects had abnormal esophageal motility disease. According to our data, the $95 \%$ percentile of percent time at below $\mathrm{pH} 4.5$ was $1.01 \%$. We suggest that $\mathrm{pH} 4.5$ should be considered as baseline for laryngopharyngeal reflux in Chinese subject. Reflux should be considered normal if the percent time at $\mathrm{pH}$ less than 4.5 is no more than $1 \%$.

In conclusion, this study suggested Chinese normal values for acid reflux using the Restech oropharyngeal $\mathrm{pH}$ probe. Further studies are needed to evaluate the utility of the Dx-pH 
measurement system and to validate the normal values of oropharyngeal $\mathrm{pH}$ in a larger number of subjects.

\section{References}

1. Vakil N, van ZSV, Kahrilas P, Dent J, Jones R; Global Consensus Group. The Montreal definition and classification of gastroesophageal reflux disease: a global evidence-based consensus. Am J Gastroenterol 2006;101:1900-1920.

2. Jung HK. Epidemiology of gastroesophageal reflux disease in Asia: a systematic review. J Neurogastroenterol Motil 2011;17:14-27.

3. Locke GR 3rd, Talley NJ, Fett SL, Zinsmeister AR, Melton LJ 3rd. Prevalence and clinical spectrum of gastroesophageal reflux: a population-based study in Olmsted County, Minnesota. Gastroenterology 1997;112:1448-1456.

4. Wong WM, Lai KC, Lam KF, et al. Prevalence, clinical spectrum and health care utilization of gastro-oesophageal reflux disease in a Chinese population: a population-based study. Aliment Pharmacol Ther 2003;18:595-604.

5. Ma XQ, Cao Y, Wang R, et al. Prevalence of, and factors associated with, gastroesophageal reflux disease: a population-based study in Shanghai, China. Dis Esophagus 2009;22:317-322.

6. Xu DT, Feng GJ, Zhao LL, Liu YL. Relationship among symptoms, mucosal injury, and acid exposure in gastroesophageal reflux disease. Chin Med J 2013;126:4430-4434.

7. Katz PO, Gerson LB, Vela MF. Guidelines for the diagnosis and management of gastroesophageal reflux disease. Am J Gastroenterol 2013;108:308-328.

8. Chong VH. Laryngopharyngeal reflux is not always secondary to gastroesophageal reflux. Eur Arch Otorhinolaryngol 2010;267:321322.

9. Koufman JA, Aviv JE, Casiano RR, Shaw GY. Laryngopharyngeal reflux: position statement of the committee on speech, voice, and swallowing disorders of the American Academy of OtolaryngologyHead and Neck Surgery. Otolaryngol Head Neck Surg 2002;127: 32-35.

10. Feng GJ, Liu YL. Some imagine for classification of LPRD from a gastroenterologist. J Gastroenterol Hepatol 2009;24(suppl 1):A5.

11. Belafsky PC, Postma GN, Koufman JA. Validity and reliability of the reflux symptom index (RSI). J Voice 2002;16:274-277.

12. Belafsky PC, Postma GN, Koufman JA. The validity and reliability of the reflux finding score (RFS). Laryngoscope 2001;111:13131317.

13. Koufman JA. Laryngopharyngeal reflux is different from classic gastroesophageal reflux disease. Ear Nose Throat J 2002;81(suppl 2):7-9.

14. Moon W, Park MI, Park SJ, Kim KJ, Lee KD. Ambulatory 24-hour pharyngeal $\mathrm{pH}$ monitoring in healthy Korean volunteers. Dig Dis Sci 2009;54:2598-2605.

15. Sun G, Muddana S, Slaughter JC, et al. A new $\mathrm{pH}$ catheter for laryngopharyngeal reflux: normal values. Laryngoscope 2009;119:16391643.

16. Wiener GJ, Tsukashima R, Kelly C, et al. Oropharyngeal pH monitoring for the detection of liquid and aerosolized supraesophageal gastric reflux. J Voice 2009;23:498-504.

17. Zheng GX ZYL. [Abnormal sensation of throat and $\mathrm{pH}$ monitoring in GERD.] Journal of Shanxi Medicine 1995;24:509-510, 512. [Chinese]

18. Cheng RX WXJ. [Clinical study on 67 GERD patients]. Zhejiang Medicine 1998;20:722-724. [Chinese]

19. Feng GJ, Zhang LH, Zhao LL, Liu YL. [A pilot study on diagnosing laryngopharyngeal reflux disease by $\mathrm{pH}$ monitoring in laryngopharynx.] Zhonghua Yi Xue Za Zhi 2008;88:805-808. [Chinese]

20. Feng GJ, Zhao LL, Zou N, Liu YL. [Symptom-based relationship between gastroesophageal reflux disease and laryngopharyngeal reflux disease.] Zhonghua Yi Xue Za Zhi 2011;91:2472-2475. [Chinese]

21. Ouyang T, Tang SX, Zhang LT, et al. [Clinical research of 24-hour double-probe $\mathrm{pH}$-metry in the laryngopharyngeal reflux diseases.] Zhonghua Er Bi Yan Hou Tou Jing Wai Ke Za Zhi 2012;47:320323. [Chinese]

22. $\mathrm{VH}$, Jalihal A. Heterotopic gastric mucosal patch of the esophagus is associated with higher prevalence of laryngopharyngeal reflux symptoms. Eur Arch Otorhinolaryngol 2010;267:1793-1799.

23. Salminen $P$, Ovaska J. Heterotopic gastric mucosal patch in patients with reflux laryngitis: an entity of clinical interest. Surg Laparosc Endosc Percutan Tech 2009;19:361-363.

24. Wang AJ, Liang MJ, Jiang AY, et al. Gastroesophageal and laryngopharyngeal reflux detected by 24-hour combined impedance and pH monitoring in healthy Chinese volunteers. J Dig Dis 2011;12: 173-180.

25. Wo JM, Jabbar A, Winstead W, Goudy S, Cacchione R, Allen JW. Hypopharyngeal $\mathrm{pH}$ monitoring artifact in detection of laryngopharyngeal reflux. Dig Dis Sci 2002;47:2579-2585. 